\title{
INTERNATIONAL LAW AND SOCIAL SCIENCE: A MILD PLEA IN AVOIDANCE
}

\author{
By Myres S. McDougal*
}

It may appear ungracious to respond questioningly to an appraisal so extensive and generous as that offered by Professor Young. The intellectual issues his statement raises transcend, however, ordinary considerations of reciprocal graciousness and generosity: innocent bystanders might be confused and misled. Professor Young purports to criticize our recommended policy-oriented jurisprudence without making explicit his own jurisprudence or the premises and assumptions which underlie his criticisms. Many of the difficulties and obscurities he finds in our work would appear to derive either from the inherent difficulties of inquiry and decision or from obscurities and incomplete notions in his own framework of inquiry. His conceptions, in particular, of "law," "international law," "world public order," "values and norms," "jurisprudence," and "social science" are less than clear. We briefly illustrate.

The conception of law we recommend is that of a process of authoritative decision, in which patterns of authority are conjoined with patterns of control. Professor Young complains that this makes law "a highly changeable or volatile phenomenon," with the result that in some situations "it is apt to become exceedingly difficult to characterize the state of 'the law' in a social system." He adds that our conception includes so much that it is non-parsimonious, creating "a real problem for anyone who sets out to explore the connections between the law of a social system on the one hand, and the changing distribution of power or the evolution of authority relations in the system, on the other." One can only wonder what empirical references he is here giving to the terms "law," "power," and "authority relations" and how he would relate these references to each other. The tenor of most of his questions and many explicit passages suggest that he is working from very conventional Austinian conceptions. Thus, he "cannot think of any major conception of law" which would incorporate "most political rules, social norms, habitual patterns of behavior, and so forth into the category of law." Yet even the Austinian conceptions make a place for "habitual patterns of behavior"! We confess that our concern is not merely for making inquiry easy and parsimonious, but for increasing the effectiveness of both inquiry and authoritative decision in a world which is, unfortunately, complex.

Viewing the world scene as a whole, we find it possible, as do many others, to observe transnational processes of authoritative decision in which conjoined patterns of authority and control are diffused about the globe in varying geographic reach, with some patterns embracing the

" Of the Board of Editors. 
whole global arena. Professor Young insists that because of "the decentralized, loosely integrated, non-institutionalized, and rapidly changing qualities" of "the international system" it is "extremely difficult to identify with any clarity its decision-making process." Even the distribution of "power in the instrumental sense" is greatly debated among scholars. "It can be argued cogently," he summarizes, "that the international system as such does not exhibit a general decision-making process that yields effective and authoritative decisions concerning the distribution of values in the system." The wonder is not that scholars who, like Professor Young, look at the world with inadequate theories, such as the Austinian dogma that law is limited to the perspectives and operations of nation-state officials, should be myopic in their vision, but that they see as much as they do. The difficulties in their theories are not of course likely to make the facts of transnational decision, with its continuously changing patterns of authority and control and increasingly important impacts upon the global distribution of values, go away.

For convenience in performing the different intellectual tasks involved in inquiry and decision, we break the more comprehensive global process of authoritative and controlling decision into constitutive decisions, those which establish the process of decision, and public order decisions, those which establish the protected features of various value processes, such as of wealth, enlightenment, health, respect and so on. Since authoritative decision protects, as well as builds upon, authority, the broadest conception of public order we recommend makes reference to the authoritatively protected features of all value processes. Professor Young finds it difficult to understand how "features of the social and political processes of the international system" are "somehow protected by the pattern of legal decisions." For him "world order is basically a political condition" and "it is hard to see any uniquely legal element, point of view, or methodology embedded in the phenomenon of world order itself, unless the whole notion of world order is simply absorbed into the category of legal analysis by definitional fiat." It would be enlightening to know by what "definitional fiat" Professor Young is here ascribing references to "political conditions," "legal elements," and "world order itself." What, most importantly, he ignores is that values are at stake and their distribution affected in all authoritative decisions. Surely he cannot be suggesting that naked power decisions alone affect the distribution of values in the larger community. It is unhappily much too common a practice among social scientists, as well as among some unenlightened lawyers, to accept a limited, conventional, and parochial conception of law; to observe triumphantly that no "law" in this limited sense obtains in the world arena; and to conclude, hence, that naked power reigns supreme in "international relations" or "the international system."

In contradistinction to merely "sociological" emphases, we recommend the deliberate, explicit postulation of a comprehensive set of human dignity values and the systematic, continuous detailed clarification of these values by performance of a whole range of interrelated intellectual tasks, 
including the description of past trends in decision, inquiry about factors affecting decision, the projection of future trends in decision, and the invention and evaluation of policy alternatives. For the relation of the most general community policies to the specific choices that must be made in application in particular instances, we suggest detailed principles of content and procedure. Professor Young observes that it is highly doubtful whether the various components of this conception of human dignity," in terms of maximizing the production and sharing of values, "are genuinely compatible." "Does maximum participation," he asks inter alia, "in determining the distribution of values always support the goal of maximizing the production of new values?" In pluralistic communities, with many different types of participants and honoring a wide range of value demands, the most fundamental, the most intensely demanded, general community policies will of course always be formulated in complementary form, and choices will have to be made between these policies in particular instances. The realistic question is whether these choices are to be made by the criteria of mysticism or obscurantism or by theory and procedures designed best to promote long-term aggregate common interest. It is a layman's fantasy to hope that some set of words can be found to make choice easy or automatic.

On particular issues, Professor Young finds that we have adhered to "an essentially orthodox type of anti-Communism," have exhibited "a somewhat naive faith in the superiority of the American system of democracy," and have demonstrated no "marked sympathy or empathy for the very real pressures motivating various groups to employ coercion to achieve social change in the contemporary world." Professor Young explains these attitudes by reference to "the prevailing atmosphere" during our formative years in the 1940's and notes that "outlooks on the problems of democracy, totalitarianism, and the use of force to achieve social change were, after all, radically different during the 1940's than they are today." He may be assured that, whatever the conditioning factors, we expect to continue our opposition to all forms of totalitarianism and to prefer the shared power of authoritative decision to intense coercion and violence as instruments of change. His criticism of specific legal interpretations would gain strength if he, or others, would demonstrate that our interpretations were mistaken by criteria related to general community expectation and long-term common interest.

The conception of jurisprudence we recommend is that of theory and procedures appropriate for inquiry about law and the interrelations of law and social process. Professor Young states that we rely upon "a highly developed and self-consciously formulated conceptual apparatus," designed by Harold Lasswell "for the study of society" and adapted "with his active assistance" for "use in legal analysis." He questions, and has difficulty in answering, "whether the Lasswellian conceptual apparatus is a necessary part of McDougal's jurisprudence." From our perspective, the "intellectual apparatus" is the jurisprudence; inquiry about law and society, and their interrelations, is one integrated enterprise requiring 
comprehensive theory and not anecdotal dabbling. Professor Young's concern about the boundaries of the different intellectual disciplines is a whimsical irrelevance.

What we offer as a set of questions to guide inquiry Professor Young characterizes as "a rigid formalism that frequently makes it difficult to fit observations of the real world into the framework's categorizations with any comfort." He concludes that "it is not possible to make significant contributions of a creative or innovative sort in the realm of legal scholarship solely by applying this conceptual apparatus in a rote fashion." Rigidity in semantic and syntactic references may, like beauty, inhere in the eyes of the beholder, rather than in the observed, and we are happy to yield exclusive reliance upon theory and rote applications to others; what we do suggest is that only a problem-oriented, contextual, and multi-method jurisprudence, emphasizing theory at all levels of abstraction and employing many different intellectual procedures, can offer any assurance of rationality in recommendation and choice and, hence, in the optimalizing of the aggregate flow of decision.

We had thought that a conception of social science, relevant to inquiry about law, might include, even as jurisprudence includes, both the formulation of appropriate theory and the performance of a range of intellectual tasks in search of new knowledge. Professor Young, however, distinguishes between "the development of a policy-oriented jurisprudence" and "the use of findings from the social sciences in legal analysis" and never specifies either what he means by "the findings of social science" or the different intellectual tasks involved in "legal analysis." $\mathrm{He}$ insists that the development of conceptual frameworks cannot be regarcled "as making legal analysis somewhat more like social science in form or method, if not in substance" because "the employment of such frameworks is both highly controversial and far from universal in the social sciences themselves." Elsewhere he describes different attitudes toward frameworks as "related to a recurring controversy in Western thinling which focuses on the notion of rationalism." One would have thought that the principal difference between social scientists, as between lawyers, was in the degree to which they were aware of their conceptual frameworks and made them explicit and that however difficult the quest for "rationality," in the sense of relating appropriate means to desired ends, we have little choice but to continue the quest.

The evidence of the use of the "substantive content" or "findings" of social science that Professor Young demands of us, and finds wanting, is, weirdly enough, that of the citation of social scientists. One is reminded of Valentinian's Law of Citations (circa 426 A.D.) which weighed responsa prudentium quantitatively, by the number of adherents; ${ }^{1}$ we prefer to

1 W. W. Buckland describes the "Law of Citations" as follows:

"Under the provisions of this statute (i) all writings of Papinian, Paul, Ulpian, Modestinus and Gaius were confrmed and might be cited, Gaius to have the samo authority as the others, (ii) any writer cited and approved by any of the five (Scaevola, Sabinus, Julian and Marcellus are named as examples) might himself be cited, provided comparison of MSS. shewed the citation to be accurate, and (iii) the 
be faithful to Cynara after our own fashion. In his closest approach to identifying intellectual tasks relevant to inquiry about law, Professor Young indicts the "apparatus" with which we work for having failed, like most other apparatus, in "the development of any theory (or theories) in the formal sense." Our framework, he insists, even "tends to hinder the development of theory severely by introducing excessive numbers of potentially relevant factors, while the crucial problem in developing viable formal theories is to construct simple logical models by stripping away as many factors as possible without undermining the predictive accuracy of the resultant propositions." The "simple logical models" to which Professor Young aspires are not of course the only modalities for making inquiry about the factors affecting authoritative decision. Taken alone, such formal theories are, further, hopelessly inadequate for guiding performance of other intellectual tasks indispensable to both inquiry and decision, such as the detailed clarification of community policies, the appraisal of past experience, the estimating of future probabilities, and the invention and evaluation of new alternatives in decision process. A social science which would aspire to contribute to understanding of authoritative decision must be more ambitious in its reach-more contextual, more problem-oriented, more multi-method-than that which hides in Professor Young's conception."

itudex must adopt the view of the majority: in case of equality, Papinian must be followed, but if he was silent the iudex might form his own judgment." A Manual of Roman Private Law 20 (2d ed., 1957).

Elsewhere he adds: "These provisions shew that scientific study of law was a thing of the past: they mark probably the lowest point reached by Roman jurisprudence." A Textbook of Roman Law 35 (1921).

2 Some of the more relevant perspectives are outlined in Professor Young's books, A Systematic Approach to International Politics (1968) and Systems of Political Science (1968). For a more detailed discussion of many of the issues raised in Professor Young's paper, with appropriate citation of his books, see Lasswell and McDougal, "Criteria for a Theory About Law," 44 So. Calif. Law Rev. 362 (1971).

Perhaps it should be added that the editorial "we" I have employed in writing this response is intended to refer not simply to one or two persons but to a larger group of associates who share certain perspectives and are making varying individual contributions to the further development of these perspectives. 